\title{
INVESTMENT SIZE AND FIRM'S VALUE UNDER PROFIT SHARING REGULATION
}

\author{
MiCHELE MORETTO \\ PAOLO M. PANTEGHINI \\ CARLO SCARPA \\ CESIFO WORKING PAPER NO. 1040 \\ CATEGORY 1: PUBLIC FinANCE \\ SEPTEMBER 2003 \\ An electronic version of the paper may be downloaded \\ - from the SSRN website: www.SSRN.com \\ - from the CESifo website: www.CESifo.de
}




\title{
INVESTMENT SIZE AND FIRM’s VALUE UNDER PROFIT SHARING REGULATION
}

\begin{abstract}
In this article we analyse the effects of different regulatory schemes (price cap and profit sharing) on a firm's investment of endogenous size. Using a real option approach in continuous time, we show that profit sharing does not affect a firm's start-up decision relative to a pure price cap scheme. Unless the threshold after which profit sharing intervenes is very high, however, introducing a profit sharing element delays further investments: this decreases the present value of total investment. We also evaluate the reduction in the firm's value due to profit sharing, linking this reduction to the option value of future investments.
\end{abstract}

JEL Code: L51, D81, D92, G31.

Keywords: regulation, investment, profit sharing, real options, RPI-x.

\author{
Michele Moretto \\ Dipartimento di Scienze Economiche \\ Università di Brescia \\ Via S. Faustino, $74 b$ \\ 25122 Brescia \\ Italy
}

\author{
Paolo M. Panteghini \\ Dipartimento di Scienze Economiche \\ Università di Brescia \\ Via S. Faustino, $74 b$ \\ 25122 Brescia \\ Italy \\ Panteghi@eco.unibs.it
}

\author{
Carlo Scarpa \\ Dipartimento di Scienze Economiche \\ Università di Brescia \\ Via S. Faustino, $74 b$ \\ 25122 Brescia \\ Italy
}




\section{Introduction}

The performance of regulated public utilities has raised concern about how to reconcile consumers' protection and the incentive to invest. A popular solution among regulators is the (by now traditional ${ }^{1}$ ) $R P I-x$ scheme, which is supposed to provide the regulated firm appropriate incentives to invest, making the regulated price insensitive to cost-reducing investments: in this way, firms which reduce their costs are not penalized. However, sometimes this rule allows the firm to keep huge profits, and this has lead to proposals to force firms to share their "excess" profit with the consumers (among others, Sappington and Weisman, 1996; Burns, Turvey and Weyman Jones, 1998). As documented for instance by Sappington (2002) there are now many cases where price cap regulation is modified with an earnings sharing clause, whereby if profits are too high there is an automatic mechanism which riveses prices, to the benefit of consumers. But - although the evidence is mixed the blanket seems to be too short: a redistribution of benefits from the firms to the consumers may decrease the incentive to invest ${ }^{2}$.

This paper analyses and assesses the above concern, in order to understand whether profit sharing schemes actually penalize investment decisions, relative to a pure price cap. This is done on the basis of modern investment theory $^{3}$, which stresses how investment is irreversible, and calls for a set-up where investment timing and uncertainty play a substantial role. Along these lines, Panteghini and Scarpa (2003a) use a simple framework to show that modifying a price cap with an element of profit sharing does not affect the incentive to make an investment of given amount: the timing and probability of such an investment are the same, independently of the presence of profit sharing.

In this paper we consider the - more plausible - set-up where time is a continuous variable and uncertainty never disappears from the market. Moreover, and more important, investment size is endogenous: the firm can

\footnotetext{
${ }^{1}$ According to this scheme, the regulated price should start from a given level, and then increase at a rate equal to the difference between the expected inflation rate (the Retail Price Index, $R P I)$ and an exogenously given component $(x)$. See Beesley and Littlechild (1989).

${ }^{2}$ On this point, among others, see Mayer and Vickers (1996) and Weisman (2002). See Ai and Sappington (2002) on the evidence, which lends some (but limited) support to this fear.

${ }^{3}$ In particular, we will use the concept real option; see for instance Dixit and Pindyck (1994).
} 
make an initial investment and then has the option to expand the plant, so that total investment size depends on several subsequent decisions. In this set-up, we can show that the initial investment does not depend on whether or not the price cap rule has a profit sharing element. The reason is that the introduction of the profit ceiling into a $R P I-x$ scheme decreases the net present value of the investment, but also decreases the value of waiting (i.e., the option value) by exactly the same amount ${ }^{4}$.

Profit sharing matters only if the threshold after which profits are passed on to consumers is low, and in this case we have an underinvestment result. When the firm reaches the threshold profit level, beyond which the price cap becomes tighter in order to transfer part of the benefits to the consumers, it faces a problem. Any increase in (profitable) investment will be self defeating, unless market profitability is so high to more than compensate profit sharing. Therefore, the firm waits until market conditions are substantially more favorable, and investment is delayed and possibly never carried out.

This paper is linked to two streams of literature. The first one is the traditional theory of investment under regulation, where investment ("effort") is fully reversible and is modelled in a static framework where the firm perfectly knows the return from its investment (e.g., Laffont and Tirole, 1986). The same approach was taken by several papers which analyze the debate on price cap and profit sharing rules. In general this literature claims that a pure $R P I-x$ system is preferable to a price cap with profit sharing, on the ground of technical efficiency (e.g., Lyon, 1996). Weisman (1993) shows that when price cap rules incorporate an element of profit sharing, price caps may represent a worsening relative to a pure cost based regulation, a notoriously inefficient set-up.

These models are perfectly suitable to tackle reversible investment. When irreversibility matters, however, the decision to invest should consider the option value of investment. As an irreversible choice entails giving up an opportunity, the value of waiting should be considered. Introducing these elements in the model necessarily requires one to analyze a dynamic model (where the timing of investment can be modelled) and to explicitly consider uncertainty, so that waiting is valuable as the information available to the firm changes over time. This change in viewpoint is also reflected in the

\footnotetext{
${ }^{4}$ This is an application of the "bad news principle" (Bernanke, 1983), which indicates that, under investment irreversibility, uncertainty acts asymmetrically since only the unfavorable events affect the current propensity to invest. If, thus, profit sharing (i.e., the change in the $x$ factor) occurs only in the good state, investment decisions are not affected.
} 
result, which is considerably less negative for profit sharing, which interferes with investment decisions only under certain conditions. Notice that this is in line with several empirical analyses, which point out that the supposed superiority of pure price cap schemes in providing incentives to investment is not based on any clear empirical evidence ${ }^{5}$.

The second stream of literature is the one on investment and irreversibility. In that framework (see e.g., Dixit and Pindyck, 1994) the case of unregulated firms is widely considered, while less attention has been paid to firms who are constrained in their pricing decisions. A notable exception is Dixit (1991), who studies the effects of price ceilings in a competitive industry. In particular, he shows that the price ceiling affects one-off investment strategies only if it low enough. Although consistent with our result, Dixit's finding does not refer to a monopoly and especially it does not include an earnings sharing clause in the price constraint.

The next section introduces the basic continuous time model. Section 3 analyses the effects of regulation with an investment of given size. Section 4 , by introducing the possibility to expand the initial investment, considers an investment of endogenous size, and contains our main result. Section 5 summarizes the results and discusses their implications.

\section{The model}

In this section we present a continuous time model of investment for a firm, subject to a regulatory constraint on its price. The firm has both an option to delay initial investment and an option to expand it. The following assumptions hold:

1. Market demand $q(t)$ follows a geometric Brownian motion

$$
d q(t)=\alpha_{q} q(t) d t+\sigma_{q} q(t) d z(t)
$$

where $t$ is time, $\alpha_{q}$ and $\sigma_{q}$ are the (constant) growth rate and variance parameter, respectively and $d z(t)$ is the increment of a standard Wiener process satisfying the conditions that $E(d z)=0$ and $E\left(d z^{2}\right)=d t$.

2. Only one firm operates in this market. Its payoff is

$$
\Pi(t)=\Psi(K(t)) p(t) q(t) \equiv \Psi(K(t)) \Theta(t)
$$

\footnotetext{
${ }^{5}$ For instance, Ai and Sappington (2002) show extremely mixed results.
} 
where $p(t)$ is the regulated price, net of costs and $\Psi(K(t))$ describes the effects of capital accumulation on the firm's profitability. This term can be thought of as a mark up. According to the above assumption, investment can be cost-reducing (namely it can lead to an increase in the firm's mark up).

3. $\Psi(0)=0 ; \Psi_{K}>0 ; \Psi_{K K}>0$ if and only if $K \in\left[0, K^{*}\right] ; \Psi_{K K}<0$ thereafter.

Assumption 3 has a Marshallian flavor, as it assumes the existence of increasing returns when $K$ does not exceed $K^{*}$. When, instead, $K \geq K^{*}$, capacity expansion is subject to diminishing marginal returns. In this case, Dixit (1995) shows that there exists an optimal starting level of capital, say $\underline{K}$ : if the firm decides to invest, it will never invest less than $\underline{K}$. This level is characterized by $\Psi_{K}(\underline{K})=\frac{\Psi(\underline{K})}{\underline{K}}$ and $\Psi_{K K}(\underline{K})<0$; this implies that $\underline{K}>K^{*}$. Once the start-up decision is made, investment decisions follow an incremental strategy ${ }^{6}$.

Let us next turn to the regulatory schemes. The basic one is an $R P I-x$ scheme, whereby price follows a pre-set dynamics given by the $x$ factor. If the firm starts producing at time zero, the initial price $p_{0}>0$ is given, and its dynamics are defined by the difference between the inflation rate (changes in the retail price index, $R P I$ ) and an exogenous factor $x_{l}$ :

$$
p(t)=p_{0} e^{\left(R P I-x_{l}\right) t}
$$

When profit sharing is introduced to complement the basic price cap formula, this entails an upper bound to the profit level, $\tilde{\Pi}$, after which a higher $x$ factor applies $^{7}$. Profit sharing is therefore defined as a modification of (3), as follows

$$
p(t)=p_{0} e^{\left(R P I-x_{j}\right) t} \text { where } x_{j}= \begin{cases}x_{l} & \text { if } \Pi[K(t), \Theta(t)]<\tilde{\Pi} \\ x_{h} & \text { if } \Pi[K(t), \Theta(t)]>\tilde{\Pi}\end{cases}
$$

with $x_{l}<x_{h}$. These parameters are known in advance by all market participants, and they are set irreversibly.

\footnotetext{
${ }^{6}$ It is worth noting that the quality of our results would not change if we assumed that the start-up level of capital were given exogenously. In this case, if $\underline{K}$ were such that $\Psi_{K}(\underline{K})>\frac{\Psi(\underline{K})}{\underline{K}}$, the firm would anyway choose a higher level of $K$ (such that $\Psi_{K}(K)=$ $\left.\frac{\Psi(K)}{K}\right)$. The only relevant case would be one in which $\Psi_{K}(\underline{K})<\frac{\Psi(\underline{K})}{\underline{K}}$.

${ }^{7}$ There are other possibilities to model profit sharing; see Sappington and Weisman (1996) and Schmalensee (1979) for (qualitatively analogous) formulations.
} 
Given (2) and (4), for any value of $K(t)$ there exists an upper value $\tilde{\Theta}(K(t))$ beyond which the regulator switches from $x_{l}$ to $x_{h}$. To compute the switch level, set

$$
\Psi(K(t)) \Theta(t)=\tilde{\Pi}
$$

and solve for $\Theta(K(t))$, so as to obtain the switch level $\tilde{\Theta}(K(t))=\frac{\tilde{\Pi}}{\Psi(K(t))}$. It is easy to ascertain that by assumption $3 \frac{d \tilde{\Theta}(K(t))}{d K(t)}<0$ for all $K(t)$.

In order to determine the dynamics of profit, we need to compute the risk-adjusted rate of return or the net "cost of carry" $(r-\delta)$, where $r$ is the risk-free interest rate and $\delta$ is the dividend rate $^{8}$. If the shareholders are risk-neutral, under equilibrium the equality $r-\delta=\alpha \geq 0$ holds $^{9}$.

Given the above equality, we have $r-\delta=R P I-x_{j}+\alpha_{q}$, with $j=l, h$. Solving for the dividend rate we thus obtain

$$
\delta\left(x_{j}\right)=r-R P I+x_{j}-\alpha_{q}, \text { with } j=l, h .
$$

Using equations (1), (2) and (3), and applying Itô's lemma we can obtain the profits' dynamics

$$
\begin{aligned}
d \Pi(t) & =\Psi_{K}(K(t)) \Theta(t) d K+\Psi(K(t)) d \Theta(t) \\
& =\Gamma(K(t)) \Pi(t) d K+\Pi(t)\left[\alpha_{j} d t+\sigma d z(t)\right], \text { with } j=l, h .
\end{aligned}
$$

where $\alpha_{j} \equiv R P I-x_{j}+\alpha_{q}$ is the expected growth rate of per-period profits, $\sigma=\sigma_{q}$ is the standard deviation, and $\Gamma(K(t)) \equiv \Psi_{K}(K(t) / \Psi(K(t))>0$ captures the direct effect of investment. From (6), we can see that investment affects the level of profit through its effect on the marginal product of capital which depends on the initial stock of capital. In particular if no new investments are undertaken, $d K=0$ profits and are driven only by exogenous shocks.

Let us now use these results in the two cases we consider. For simplicity, hereafter, we will omit the time variable $t$.

\footnotetext{
${ }^{8}$ Notice that the dividend rate must be positive for the net value of the firm to have an upper bound.

${ }^{9}$ If shareholder are risk-averse, the difference $r-\delta$ takes account of a the risk premium. However, the quality of results is unaffected. For further details see McDonald and Siegel (1986).
} 


\section{The start-up decision}

Let us first analyze the start-up decision. Given Assumption $3, \underline{K}$ is given by technological conditions. We therefore concentrate on profit maximization given this level of capital.

It is known from investment theory that investment will take place if current profit goes beyond a certain "trigger" level. If $\widetilde{\Pi}$ is below this trigger point, the price scheme would start with $x_{j}=x_{h}$. In this case, the $x$ factor would remain constant, exactly like in pure price cap case. Therefore, to have a real alternative to price cap, we must assume that $\widetilde{\Pi}$ is greater than the trigger point; in this way, regulation starts with a value of $x_{j}=x_{l}$, which is made more stringent at a later stage, in case profit goes beyond $\widetilde{\Pi}$.

Given (2) we can express this trigger point in terms of $\Theta$. As there are two logical steps (start-up $(S)$ and expansion $(E)$ ) we can think of the optimal investment policy as a function $\Theta^{*}(K)$, as follows

$$
\Theta^{*}(K) \equiv\left\{\begin{array}{cc}
\Theta_{S}^{*}(K) & \text { for } K=\underline{K} \\
\Theta_{E}^{*}(K) & \text { for } K>\underline{K}
\end{array}\right.
$$

Let us start characterizing the start-up decision, i.e. $\Theta_{S}^{*}(K)$. The firm decides whether and when to start the project of dimension $\underline{K}$, by solving a standard optimal stopping time problem. In other words, it chooses the investment timing which maximizes

$$
O(\underline{K}, \Theta)=\max _{T} E_{0}\left\{\left[V(\underline{K}, \Theta(T))-p_{K} \underline{K}\right] e^{-r T} \mid \Theta_{0}=\Theta\right\}
$$

where $E_{0}\{\cdot\}$ denotes the expectation operator with the information available at time zero, $V(\cdot)$ is the project value, i.e. the $N P V$ of the project at time $T$, and $p_{K}$ is the price of capital. Thus, $O(\cdot)$ represents the value of the option to delay the start-up decision.

Given the above assumptions, therefore, one obtains the following

Proposition 1 The candidate policy for optimal start-up is described by the following upper threshold:

$$
\Theta_{S}^{*}(\underline{K}) \equiv \frac{\beta_{1}\left(x_{l}\right)}{\beta_{1}\left(x_{l}\right)-1} \delta\left(x_{l}\right) \frac{p_{K} \underline{K}}{\Psi(\underline{K})}
$$


Proof. See Appendix.

The optimal time of investments will be defined as $T^{*}=\inf (t>0 \mid \Theta=$ $\left.\Theta_{S}^{*}(\underline{K})\right)$. Proposition 1 shows that the optimal start-up threshold depends only on the factor $x_{l}$. In particular, $\Theta_{S}^{*}(\underline{K})$ does not depend on the switch point $\tilde{\Pi}$ : as profit sharing does not affect the start-up decision, the neutrality result found in Panteghini and Scarpa (2003a) is confirmed. Proposition 1 also shows that this threshold depends on the average productivity of capital, $\frac{\Psi(\underline{K})}{\underline{K}}$.

\section{The option to expand: profit sharing and the size of investment}

In order to analyze how regulatory constraints affect how much a firm invests, we assume that once the firm decides to make an initial investment, it has the possibility to invest further. Again, subsequent expansions will be decided if and when the current profit level reaches different thresholds.

These expansions are assumed to be irreversible. Technically, this means that, by exercising the option to delay, the firm acquires a compound option to expand, which consists of a continuum of American call options, each for any $d K$. For any given starting value of capital the firm can exercise a call option to expand production. After the exercise of such an option the firm obtains another American call option allowing it to undertake a further increment.

In most real-world settings, the ability to expand capacity is limited. In particular, firms operating in regulated markets face both institutional and technological limits, which prevent their production to go beyond a maximum level ${ }^{10}$. Therefore, we assume that a maximum quantity of capital $\bar{K}$ exists. The compound option is completely exercised when the firm reaches this level.

The first thing to check is whether the trigger point $\Theta_{S}^{*}(\underline{K})$ depends on this possibility to expand the initial investment. To see whether this is the case, let us rewrite (9) as

$$
\frac{\Psi(\underline{K}) \Theta_{S}^{*}(\underline{K})}{\delta\left(x_{l}\right)} \equiv \frac{\beta_{1}\left(x_{l}\right)}{\beta_{1}\left(x_{l}\right)-1} p_{K} \underline{K}=p_{K} \underline{K}+\frac{p_{K} \underline{K}}{\beta_{1}\left(x_{l}\right)-1}
$$

\footnotetext{
${ }^{10}$ For a discussion on limited expandability, see Dixit and Pindyck (2000).
} 
According to (10), the firm will make the initial investment when the present value of the project at entry, $\frac{\Psi(\underline{K}) \Theta_{S}^{*}(\underline{K})}{\delta\left(x_{l}\right)}$, equals the cost of the investment $p_{K} \underline{K}$ multiplied by a coefficient $\frac{\beta_{1}}{\beta_{1}-1}>1$. This coefficient accounts for the option value effect: by waiting a little, the firm obtains new information about market profitability, and this reduces its downside risk. When the firm makes the initial investment, the firm exercises an option to delay and therefore loses some flexibility. The cost of the net loss of flexibility (i.e. the effective opportunity cost) is given by

$$
\frac{p_{K} \underline{K}}{\beta_{1}\left(x_{l}\right)-1}
$$

When after the start up the firm may expand its capital, the start-up investment has two effects. On the one hand, it reduces the firm's flexibility (as above), but on the other hand it entails the acquisition of an option to expand production. In this case, it is straightforward to show the following

Corollary 1 The net loss of flexibility for the firm is the same, whether or not one considers an option to expand.

Proof. See Appendix.

The reason is that what matters is the difference between the value of the option to delay and the value of the option to expand. If there is no possibility to expand the initial project, the value of the latter is obviously zero. If the possibility to expand the project exists, the value of the option to expand is positive, but the value of the option to delay increases by an equal amount.

We can now study the firm's investment strategies after the start-up. To this end, the following Lemma is necessary.

Lemma 1 If $x_{l}<x_{h}$, then $\frac{\beta_{1}\left(x_{l}\right)}{\beta_{1}\left(x_{l}\right)-1} \delta\left(x_{l}\right)<\frac{\beta_{1}\left(x_{h}\right)}{\beta_{1}\left(x_{h}\right)-1} \delta\left(x_{h}\right)$.

Proof. See Appendix.

Determining how much capital the firm decides to accumulate and the timing of this process allows us to determine how the firm's investment decisions are linked to the regulatory scheme. After the initial start-up decision, investment size becomes endogenous. The following Proposition can be proven: 
Proposition 2 Let define $\tilde{K}$ the amount of capital such that

$$
\frac{\beta_{1}\left(x_{l}\right)}{\beta_{1}\left(x_{l}\right)-1} \delta\left(x_{l}\right) \frac{p_{K}}{\Psi_{K}(\tilde{K})}=\frac{\tilde{\Pi}}{\Psi(\tilde{K})} .
$$

If $\tilde{K} \in(\underline{K}, \bar{K}]$, the candidate policy for optimal investment is described by the following upper threshold:

$$
\Theta_{E}^{*}(K) \equiv\left\{\begin{array}{c}
\Theta_{P C}^{*}(K) \equiv \frac{\beta_{1}\left(x_{l}\right)}{\beta_{1}\left(x_{l}\right)-1} \delta\left(x_{l}\right) \frac{p_{K}}{\Psi_{K}(K)}, \quad \text { for } K \in(\underline{K}, \tilde{K}], \\
\Theta_{P S}^{*}(K) \equiv \frac{\beta_{1}\left(x_{h}\right)}{\beta_{1}\left(x_{h}\right)-1} \delta\left(x_{h}\right) \frac{p_{K}}{\Psi_{K}(K)}, \quad \text { for } K \in(\tilde{K}, \bar{K}] .
\end{array}\right.
$$

Proof. See Appendix.

According to Proposition 2, as long as $K<\tilde{K}$, profit sharing (namely $x_{h}$ ) does not affect investment. Only when $K \geq \tilde{K}$ does profit sharing affect capital accumulation.

With a pure price cap scheme, $\Theta^{*}(K)=\Theta_{P C}^{*}(K)$ for any value of $K$ (namely, we do not have a threshold value $\tilde{K}$ ). With profit sharing, if $\tilde{K} \in$ $(\underline{K}, \bar{K}]$ the function has two parts; the first one coincides with $\Theta_{P C}^{*}(K)$, while the second one differs. As shown in the Appendix (see (34)), for $K \geq \tilde{K}$ we have $\Theta^{*}(K)>\widetilde{\Theta}(K)$. In this case, the profit sharing constraint is binding and the relevant trigger point is $\Theta_{P S}^{*}(K)$. By Lemma 1, it is straightforward to show that under profit sharing, $\Theta_{P S}^{*}(K)>\Theta_{P C}^{*}(K)$ for any given $K \geq \tilde{K}$. This means that profit sharing increases the threshold value, beyond which the firm decides to expand its plant, and thus discourages further investment.

Corollary $2 \Theta_{P C}^{*}(\underline{K})=\Theta_{S}^{*}(\underline{K})$ as long as $\Psi_{K}(\underline{K})=\frac{\Psi(\underline{K})}{\underline{K}}$.

This Corollary confirms that when $\underline{K}$ is chosen optimally, i.e., when $\Psi_{K}(\underline{K})=\frac{\Psi(\underline{K})}{\underline{K}}, \Theta_{S}^{*}(\underline{K})$ characterizes optimal investment policy even when we consider the option to expand. The investment function $\Theta^{*}(K)$ is therefore continuous for $K=\underline{K}$. If we compare (9) with (13), given assumption 3 we can write

$$
\Theta_{S}^{*}(\underline{K})=\Theta_{E}^{*}(\underline{K})=\lim _{d K \rightarrow 0} \Theta_{P C}^{*}(\underline{K}+d K)
$$




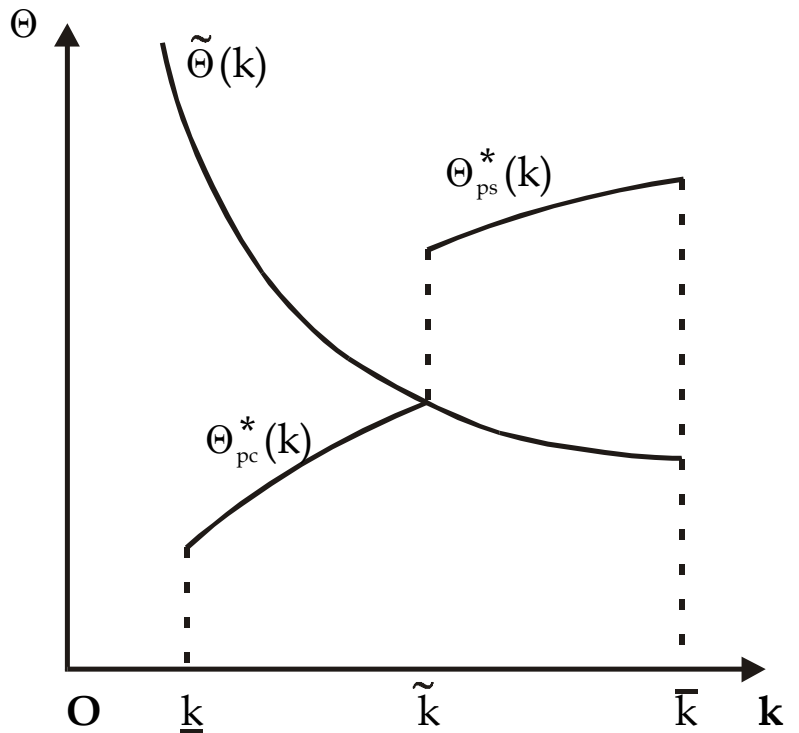

Figure 1 
In other words, the trigger point for the start-up decision is equal to the trigger point above which investing $\underline{K}+d K$ is profitable. This implies that there do not exist jumps in the trigger point ${ }^{11}$.

The optimal investment policy can be represented in Figure 1 above, which depicts $\Theta^{*}$ as a function of $K$.

The profit sharing threshold $\widetilde{\Theta}(K)$ is a decreasing function of $K$ : it is like an iso-profit curve, where a high value of $\Theta$ must be compensated by a low value of $K$. Since $\Psi_{K}(K)$ is decreasing in the region $(\underline{K}, \bar{K}]$, the optimal investment policy $\Theta^{*}(K)$ is instead upward-sloping. When $\Theta^{*}(K)=\widetilde{\Theta}(K)$, the profit sharing constraint intervenes, $x_{j}$ jumps from $x_{l}$ to $x_{h}$ and therefore $\Theta^{*}(K)$ has a discontinuity (see (13)). This happens for $K=\widetilde{K}$, which is by assumption larger than $\underline{K}$.

When $\Theta<\Theta_{P C}^{*}(K)$, the optimal policy is inaction (keeping $K$ constant). The firm waits until the stochastic process moves $\Theta$ above $\Theta_{P C}^{*}(K)$, and at this point it will be optimal to invest (to increase $K$ ). When $\Theta_{P C}^{*}(K)<$ $\Theta<\Theta_{P C}^{*}(\widetilde{K})$, a discrete investment will occur in a lump, to move the capital level immediately to the optimal policy curve, as long as the profit sharing constraint is not binding (i.e., as long as $K \leq \widetilde{K})$. When $\Theta_{P C}^{*}(\widetilde{K})<\Theta<$ $\Theta_{P S}^{*}(\widetilde{K})$ the firm cannot increase capital beyond the level $\widetilde{K}$ : further investments would push the firm beyond the threshold where profit sharing intervenes, and would thus tighten the regulatory constraint.

The firm will increase its capital level beyond $\widetilde{K}$ only when $\Theta>\Theta_{P S}^{*}(\widetilde{K})$. At such high levels of revenue, the firm finds it optimal to accept a tightening of the price rule: forgiving market opportunities would be too expensive. When $K$ reaches its maximum level $\bar{K}$, further investments are impossible and the firm can only produce at the regulated price.

We therefore see that profit sharing is neutral for low levels of investment $(K<\widetilde{K})$ and in particular for the start up decision. Moreover, profit sharing is neutral if it intervenes for large enough levels of profit (such that $\widetilde{K}>$

\footnotetext{
${ }^{11}$ If we had assumed that the start-up level of capital were given exogenously, as already pointed out, $\underline{K}$ would be such that $\Psi_{K}(\underline{K})<\frac{\Psi(\underline{K})}{\underline{K}}$. Therefore, an exogenous jump would take place after the start-up, i.e. $\Theta_{S}^{*}(\underline{K})<\Theta_{P C}^{*}(\underline{K}+d K)$. However, the $\Theta^{*}$ schedule would not change for $K>\underline{K}$, and the qualitative nature of the result would not change.
} 
$\bar{K})$, while it is distortionary otherwise, delaying - possibly, for an indefinite amount of time - large increments of the initial investment.

Let us now analyze the effect of these regulatory schemes on the firm's value. It is straightforward to show that

Proposition 3 The firm's value at time zero is

$$
V(K, \Theta)=\frac{\Pi(K, \Theta)}{\delta\left(x_{l}\right)}+A_{1}\left(K, x_{l}\right) \Theta^{\beta_{1}\left(x_{l}\right)}
$$

where

$$
\begin{gathered}
A_{1}\left(K, x_{l}\right)=\int_{z=K}^{\bar{K}}-a_{1}\left(z, x_{l}\right) d z= \\
=\left(\frac{\beta_{1}\left(x_{l}\right)-1}{p_{K}}\right)^{\beta_{1}\left(x_{l}\right)-1}\left(\frac{1}{\beta_{1}\left(x_{l}\right) \delta\left(x_{l}\right)}\right)^{\beta_{1}\left(x_{l}\right)} \int_{z=K}^{\bar{K}}\left(\Psi_{K}(z)\right)^{\beta_{1}\left(x_{l}\right)} d z+ \\
+\frac{\left(\delta\left(x_{l}\right)-\delta\left(x_{h}\right)\right)}{\delta\left(x_{l}\right) \delta\left(x_{h}\right)} \int_{z=K}^{\bar{K}} \Psi_{K}(z)\left(\frac{\Psi(z)}{\tilde{\Pi}}\right)^{\beta_{1}\left(x_{l}\right)-1} d z .
\end{gathered}
$$

Proof. See Appendix.

The firm's value consists of the sum of the static net present value $\left(\frac{\Pi(K, \Theta)}{\delta\left(x_{l}\right)}\right)$ and the option values $\left(A_{1}\left(K, x_{l}\right) \Theta^{\beta_{1}\left(x_{l}\right)}\right)$. The first part of $A_{1}\left(K, x_{l}\right)$ measures the value of the option to expand under pure price cap, and indeed it only depends on $x_{l}$. The second term is the expected loss (given that $\delta\left(x_{l}\right)<$ $\left.\delta\left(x_{h}\right)\right)$ due to a tighter regulation, which intervenes as $\Theta$ reaches the threshold $\widetilde{\Theta}(K)$. The formula shows that this loss is proportional to the expected value of the incremental investments which are delayed by the firm because of profit sharing.

This means that the value of the firm is negatively affected by profit sharing, relative to a pure price cap. To some extent, this is desirable: the very notion of profit sharing comes from the idea that a scheme which yields an excessively imbalanced distribution of rents is undesirable ${ }^{12}$. Thus, one of the regulators' main targets is the rent extraction per se, with as little distortion as possible. However, unlike Panteghini and Scarpa (2003a), here total investment size is endogenous, and profit sharing may generate a distortion in investment decisions and therefore an inefficiency. A more complete welfare evaluation of this would require a full specification of a welfare function, which is beyond the scope of the paper.

\footnotetext{
${ }^{12}$ Note that also the rate-of-return regulation scheme, still prevailing in a large part of the US, is based on the idea that restraining monopoly rents is a goal by itself.
} 


\section{Extensions and conclusion}

Despite its apparent complexity, necessary to incorporate uncertainty and time in a satisfactory way, the model still lies on certain assumptions. However, it is easy to show how the model can accommodate at least two additional factors.

Regulatory risk. We have explicitly modeled market uncertainty, while regulatory risk - the possibility that the regulator committed to a price cap mechanism betrays expectations and changes the $x$ factor because observed profits are very high - raises different issues. If revenues may be revised downwards because profits are "too high", then firm's choices will be affected. But does the introduction of earnings sharing provisions change? Panteghini and Scarpa (2003b) tackle this issue with an investment of given size, showing how uncertainty which intervenes in good states of the world (the risk that high profits will partially be shared) does not affect investment decisions. In the framework we analyze here, it would be easy to show that the same conclusion applies to the initial (start-up) investment. However, regulatory risk may affect the size of total investment, and therefore the expansion decisions. Would earnings sharing be a good way to neutralize this effect? Every decision to expand the initial investment is taken, looking at the future expected value of that expansion. In that moment, the logic governing the decision is the same which underlies the start-up. Therefore, regulatory risk linked to high profits does not modify the comparison between profit sharing and pure price cap that we have developed in the previous section.

Two-sided profit sharing. Many schemes with profit sharing do not only intervene when profits are too high, but when profits are low as well. In this way, the $x$ factor could be adjusted downwards if demand or cost conditions worsen ${ }^{13}$ and profits fall below a given threshold. This provides the firm a form of insurance against market risks and - relative to a pure price cap scheme - this gives the firm an additional incentive to invest ${ }^{14}$. Therefore, Proposition 1 would be modified in that a two-sided earning sharing scheme encourages the firm to invest sooner than with a pure price cap. Expansion investments would equally be encouraged, so that the underinvestment result

\footnotetext{
${ }^{13}$ Weisman (2002) stresses how important it would be to distinguish between these sources of low profitability. We agree with his point, which is anyway beyond the scope of these remarks.

${ }^{14}$ A provision of this type would make "bad news" less "bad" and is therefore not neutral to investment decisions.
} 
of Proposition 2 should be qualified: profit sharing leads to underinvestment (in the sense of Proposition 2) if it is one-sided, while the analysis with two-sided profit sharing would lead to a more ambiguous result.

The empirical analyses of the effects of earnings sharing schemes on investments lead to ambiguous conclusions, and our results indicate good reasons why that may be so. However, there is room for further research. In particular some of the parameters of this model, such as the values of $x$ factors and of the thresholds for profit sharing, are set by the regulator. Thus an explicit framework taking into account the determination of these values would represent a valuable extension. 


\section{Appendix}

\subsection{Proof of Proposition 1}

Using dynamic programming, the firm's value $V(\underline{K}, \Theta)$ can be written as

$$
V(\underline{K}, \Theta)=\Pi(\underline{K}, \Theta) d t+e^{-r d t} E_{0}[V(\underline{K}, \Theta+d \Theta)]
$$

Expanding the right-hand side and using Itô's lemma one obtains

$$
r V(\underline{K}, \Theta)=\Pi(\underline{K}, \Theta)+\left(r-\delta\left(x_{l}\right)\right) \Theta V_{\Theta}(\underline{K}, \Theta)+\frac{\sigma^{2}}{2} \Theta^{2} V_{\Theta \Theta}(\underline{K}, \Theta)
$$

where $V_{\Theta}(\underline{K}, \Theta)=\partial V(\underline{K}, \Theta) / \partial \Theta$ and $V_{\Theta \Theta}(\underline{K}, \Theta)=\partial^{2} V(\underline{K}, \Theta) / \partial \Theta^{2}$, respectively. The differential equation (14) has a standard closed-form solution

$$
V(\underline{K}, \Theta)=\frac{\Pi(\underline{K}, \Theta)}{\delta\left(x_{l}\right)}+\sum_{i=1}^{2} A_{i}\left(\underline{K}, x_{l}\right) \Theta^{\beta_{i}\left(x_{l}\right)},
$$

where $\beta_{1}\left(x_{l}\right)>1$ and $\beta_{2}\left(x_{l}\right)<0$ are the roots of the following characteristic equation ${ }^{15}$ :

$$
\frac{\sigma^{2}}{2} \beta(\beta-1)+\left(r-\delta\left(x_{l}\right)\right) \beta-r=0 .
$$

To compute the value function, we use the boundary condition $V(\underline{K}, 0)=$ 0 . Namely, when $\Theta$ goes to zero, the value function becomes worthless ${ }^{16}$ This implies that $A_{2}\left(\underline{K}, x_{l}\right)=0$. Notice that starting with the initial capacity $\underline{K}$, at each instant $t$ the firm has two possibilities: it may decide to add capital, or it can decide not to make further investment. Installing an additional unit of capital $d K$ entails the exercise of an option to expand. The value of the option to expand capital depends on the stock accumulated so far. Thus

\footnotetext{
${ }^{15}$ The roots are

$$
\beta_{1,2}(x)=\frac{1}{2}-\frac{r-\delta(x)}{\sigma^{2}} \pm \sqrt{\left(\frac{r-\delta(x)}{\sigma^{2}}-\frac{1}{2}\right)^{2}+\frac{2 r}{\sigma^{2}}} .
$$

It is easy to ascertain that $\frac{\partial \beta_{1}(x)}{\partial x}>0$.

${ }^{16}$ For further details on the boundary conditions see Dixit and Pindyck (1994, Ch. 5 and 6$)$.
} 
term $A_{1}\left(\underline{K}, x_{l}\right) \Theta^{\beta_{1}\left(x_{l}\right)}$ is the sum of the marginal options to increase, allowing the accumulation from the current amount of capital $\underline{K}$.

Let's now turn to the option value $O(\underline{K}, \Theta)$. As in (8), we can write

$$
O(\underline{K}, \Theta)=e^{-r d t} E_{0}[O(\underline{K}, \Theta+d \Theta)]
$$

which has the following solution

$$
O(\underline{K}, \Theta)=\sum_{i=1}^{2} B_{i}\left(\underline{K}, x_{l}\right) \Theta^{\beta_{i}\left(x_{l}\right)}
$$

As mentioned above, the initial regulatory regime is the pure price cap (with profit sharing possibly intervening only at a later stage). Thus, $B_{i}\left(\underline{K}, x_{l}\right)$ and $\beta_{i}\left(x_{l}\right)$ do not depend on $x_{h}$. Using the boundary condition $O(\underline{K}, 0)=0$, one obtains

$$
O(\underline{K}, \Theta)=B_{1}\left(\underline{K}, x_{l}\right) \Theta^{\beta_{1}\left(x_{l}\right)}
$$

where $B_{1}\left(\underline{K}, x_{l}\right)$ is a constant to be determined. The optimal investment timing can be computed using the Value Matching Condition (VMC) and the Smooth Pasting Condition (SPC). The former condition requires the net present value of the project to be equal to the option value to defer investment, namely

$$
V\left(\underline{K}, \Theta^{*}\right)-p_{K} \underline{K}=O\left(\underline{K}, \Theta^{*}\right) .
$$

The second condition requires the slopes of the functions $\left[V(\underline{K}, \Theta)-p_{K} \underline{K}\right]$ and $O(\underline{K}, \Theta)$ to match

$$
V_{\Theta}\left(\underline{K}, \Theta^{*}\right)=O_{\Theta}\left(\underline{K}, \Theta^{*}\right) .
$$

Conditions $V M C$ and $S P C$ characterize optimal investment time. Given (6), this value can be associated to a level $\Theta^{*}(\underline{K})$ : whenever current profit reaches $\Pi\left(\underline{K}, \Theta^{*}(\underline{K}),\right)$, the firm invests. To solve the optimal stopping time problem, let us substitute (15) and (16) into the $V M C$ and the $S P C$. We thus obtain a two-equation system with two unknowns: the trigger point of $\Theta$, above which investment is profitable, i.e.

$$
\Theta^{*}(\underline{K}) \equiv \Theta_{S}^{*}(\underline{K}) \equiv \frac{\beta_{1}\left(x_{l}\right)}{\beta_{1}\left(x_{l}\right)-1} \delta\left(x_{l}\right) \frac{p_{K} \underline{K}}{\Psi(\underline{K})},
$$


and the difference

$$
\left[B_{1}\left(\underline{K}, x_{l}\right)-A_{1}\left(\underline{K}, x_{l}\right)\right] \Theta_{S}^{*}(\underline{K})^{\beta_{1}\left(x_{l}\right)}=\frac{p_{K} \underline{K}}{\beta_{1}\left(x_{l}\right)-1}
$$

Term $\left[B_{1}\left(\underline{K}, x_{l}\right)-A_{1}\left(\underline{K}, x_{l}\right)\right] \Theta^{\beta_{1}\left(x_{l}\right)}$ measures the value of the option to delay, net of the option to expand. By undertaking the initial investment the firm gets an option to expand production. When the firm starts production, i.e. at $\Theta_{S}^{*}(\underline{K})$, the net loss of flexibility is $\frac{p_{K} \underline{K}}{\beta_{1}\left(x_{l}\right)-1}$.

\subsection{Proof of Corollary 1}

Let us recall (18) and let us rewrite it as

$$
B_{1}\left(\underline{K}, x_{l}\right) \Theta_{S}^{*}(\underline{K})^{\beta_{1}\left(x_{l}\right)}=\frac{p_{K} \underline{K}}{\beta_{1}\left(x_{l}\right)-1}+A_{1}\left(\underline{K}, x_{l}\right) \Theta_{S}^{*}(\underline{K})^{\beta_{1}\left(x_{l}\right)} .
$$

If now we assume that the firm does not have any option to expand, then $A_{1}\left(\underline{K}, x_{l}\right)=0$. Therefore, (19) boils down to

$$
B_{1}\left(\underline{K}, x_{l}\right) \Theta_{S}^{*}(\underline{K})^{\beta_{1}\left(x_{l}\right)}=\frac{p_{K} \underline{K}}{\beta_{1}\left(x_{l}\right)-1}
$$

which implies that the net loss of flexibility is the same whether or not the option to expand exists.

\subsection{Proof of Lemma 1}

Let us recall the positive root

$$
\beta_{1}\left(x_{j}\right)=\frac{1}{2}-\frac{r-\delta\left(x_{j}\right)}{\sigma^{2}}+\sqrt{\left(\frac{r-\delta\left(x_{j}\right)}{\sigma^{2}}-\frac{1}{2}\right)^{2}+\frac{2 r}{\sigma^{2}}}, j=l, h,
$$

which can rewritten as

$$
\beta_{1}\left(x_{j}\right)+\left(\frac{r-\delta\left(x_{j}\right)}{\sigma^{2}}-\frac{1}{2}\right)=\sqrt{\left(\frac{r-\delta\left(x_{j}\right)}{\sigma^{2}}-\frac{1}{2}\right)^{2}+\frac{2 r}{\sigma^{2}}}>0 .
$$


Differentiating $\beta_{1}\left(x_{j}\right)$ with respect to $\delta\left(x_{j}\right)$ and using (21) yields

$$
\begin{gathered}
\frac{\partial \beta_{1}\left(x_{j}\right)}{\partial \delta\left(x_{j}\right)}=\frac{1}{\sigma^{2}}\left\{1-\frac{\frac{r-\delta\left(x_{j}\right)}{\sigma^{2}}-\frac{1}{2}}{\beta_{1}\left(x_{j}\right)-\left(\frac{1}{2}-\frac{r-\delta\left(x_{j}\right)}{\sigma^{2}}\right)}\right\}= \\
=\frac{1}{\sigma^{2}} \frac{\beta_{1}\left(x_{j}\right)+\left(\frac{r-\delta\left(x_{j}\right)}{\sigma^{2}}-\frac{1}{2}\right)-\left(\frac{r-\delta\left(x_{j}\right)}{\sigma^{2}}-\frac{1}{2}\right)}{\beta_{1}\left(x_{j}\right)-\left(\frac{1}{2}-\frac{r-\delta\left(x_{j}\right)}{\sigma^{2}}\right)}= \\
=\frac{1}{\sigma^{2}} \frac{\beta_{1}\left(x_{j}\right)}{\beta_{1}\left(x_{j}\right)-\left(\frac{1}{2}-\frac{r-\delta\left(x_{j}\right)}{\sigma^{2}}\right)} . \\
\frac{\partial}{\partial \beta_{1}\left(x_{j}\right)}\left(\frac{\beta_{1}\left(x_{j}\right)}{\beta_{1}\left(x_{j}\right)-1}\right)=-\frac{1}{\left[\beta_{1}\left(x_{j}\right)-1\right]^{2}}<0 \\
=\left[\frac{\partial}{\partial \beta_{1}\left(x_{j}\right)}\left(\frac{\beta_{1}\left(x_{j}\right)}{\beta_{1}\left(x_{j}\right)-1}\right)\right] \delta\left(x_{j}\right) \frac{\partial \beta_{1}\left(x_{j}\right)}{\partial \delta\left(x_{j}\right)}+\frac{\beta_{1}\left(x_{j}\right)}{\beta_{1}\left(x_{j}\right)-1}= \\
=-\frac{\delta\left(x_{j}\right)-1}{\left[\beta_{1}\left(x_{j}\right)-1\right]^{2}} \frac{1}{\sigma^{2}} \frac{\beta_{1}\left(x_{j}\right)}{\beta_{1}\left(x_{j}\right)-\left(\frac{1}{2}-\frac{r-\delta\left(x_{j}\right)}{\sigma^{2}}\right)}+\frac{\beta_{1}\left(x_{j}\right)}{\beta_{1}\left(x_{j}\right)-1}= \\
=\frac{\beta_{1}\left(x_{j}\right)}{\beta_{1}\left(x_{j}\right)-1}\left\{1-\frac{\delta\left(x_{j}\right)}{\sigma^{2}} \frac{1}{\left[\beta_{1}\left(x_{j}\right)-1\right]\left[\beta_{1}\left(x_{j}\right)-\left(\frac{1}{2}-\frac{r-\delta\left(x_{j}\right)}{\sigma^{2}}\right)\right]}=\right. \\
=\frac{\beta_{1}\left(x_{j}\right)}{\beta_{1}\left(x_{j}\right)-1} \frac{f\left(\delta\left(x_{j}\right)\right)}{\left[\beta_{1}\left(x_{j}\right)-1\right]\left[\beta_{1}\left(x_{j}\right)-\left(\frac{1}{2}-\frac{r-\delta\left(x_{j}\right)}{\sigma^{2}}\right)\right]},
\end{gathered}
$$

where

$$
f\left(\delta\left(x_{j}\right)\right) \equiv\left[\beta_{1}\left(x_{j}\right)-1\right]\left[\beta_{1}\left(x_{j}\right)-\left(\frac{1}{2}-\frac{r-\delta\left(x_{j}\right)}{\sigma^{2}}\right)\right]-\frac{\delta\left(x_{j}\right)}{\sigma^{2}} .
$$

This implies that

$$
\frac{\partial}{\partial \delta\left(x_{j}\right)}\left(\frac{\beta_{1}\left(x_{j}\right)}{\beta_{1}\left(x_{j}\right)-1} \delta\left(x_{j}\right)\right) \propto f\left(\delta\left(x_{j}\right)\right)
$$

It is easy to ascertain that

$$
\lim _{\delta\left(x_{j}\right) \rightarrow 0^{+}} f\left(\delta\left(x_{j}\right)\right)>0
$$


Moreover, we have

$$
\frac{\partial f\left(\delta\left(x_{j}\right)\right)}{\partial \delta\left(x_{j}\right)}=\frac{\beta_{1}\left(x_{j}\right)}{\sigma^{2}} \frac{\beta_{1}\left(x_{j}\right)-1}{\beta_{1}\left(x_{j}\right)-\left(\frac{1}{2}-\frac{r-\delta\left(x_{j}\right)}{\sigma^{2}}\right)}>0, \text { for } \delta\left(x_{j}\right) \in(0, r] .
$$

Let us next recall equation (5):

$$
\delta\left(x_{j}\right)=r-R P I+x_{j}-\alpha_{q}
$$

Obviously, $\frac{\partial \delta\left(x_{j}\right)}{\partial x_{j}}=1$. Thus conditions (22) and (23) are sufficient to conclude that

$$
\frac{\partial}{\partial x_{j}}\left(\frac{\beta_{1}\left(x_{j}\right)}{\beta_{1}\left(x_{j}\right)-1} \delta\left(x_{j}\right)\right)>0 .
$$

This proves Lemma 1

\subsection{Proof of Proposition 2}

To show that system (13) provides the optimal triggers for the incremental decision, let us first define the firm's value at time zero. This is the expected discounted stream of profits $\Pi(K, \Theta) \equiv \Psi(K) \Theta$, taking into account both profit sharing regulation as well as the value of $\bar{K}$. Without loss of generality, let us assume that $\Pi \leq \tilde{\Pi}$. The firm's problem is

$$
V(K, \Theta)=\max _{K} E_{0}\left[\int_{0}^{\infty} e^{-r t}\left[\Pi(K, \Theta)-p_{K} d K\right] d t \mid K_{0}=K, \Theta_{0}=\Theta\right]
$$

such that $d K \geq 0, K \leq \bar{K}$ and (6) for all $t$. Absent installation costs, the rate of growth of capital is unbounded where $d K$ is the investment process. The expectation in equation (24) is taken with respect to the joint distribution of $K$ and $\Theta$, with $\Theta$ driven by (6), conditional on the information available at time zero and taking into account the profit sharing constraint and the irreversibility constraint.

Assuming that $V$ is twice continuously differentiable, a solution can be obtained starting within a time interval where no new investment occurs. From (24), the firm's value can be written as 


$$
V(K, \Theta)=\Pi(K, \Theta) d t+e^{-r d t} E_{0}[V(K, \Theta+d \Theta)]
$$

Expanding the right-hand side and using Itô's lemma one obtains

$$
r V(K, \Theta)=\Pi(K, \Theta)+\left(r-\delta\left(x_{l}\right)\right) \Theta V_{\Theta}(K, \Theta)+\frac{\sigma^{2}}{2} \Theta^{2} V_{\Theta \Theta}(K, \Theta)
$$

Differentiating (25) with respect to $K$, and defining by $v(K, \Theta) \equiv V_{K}(K, \Theta)$ the contribution of the $K t h$ unit of capital to the firm's value, we obtain the following differential equation

$$
r v(K, \Theta)=\Pi_{K}(K, \Theta)+\left(r-\delta\left(x_{l}\right)\right) \Theta v_{\Theta}(K, \Theta)+\frac{\sigma^{2}}{2} \Theta^{2} v_{\Theta \Theta}(K, \Theta)
$$

which has the following closed-form solution

$$
v(K, \Theta)=f(K, \Theta)+\sum_{i=1}^{2} a_{i}\left(K, x_{l}\right) \Theta^{\beta_{i}\left(x_{l}\right)} .
$$

The index $l$ in $a_{i}\left(K, x_{l}\right)$ indicates that $x=x_{l}$, i.e. that profit sharing is not in place. The interpretation of equation (27) is then transparent. The contribution of the $K t h$ unit of capital to the profit flow, when the existing stock of capital is $K$, is given by $\Pi_{K}(K, \Theta)=\Psi_{K}(K) \Theta$. Since $\Theta$ is expected to grow at the rate $\alpha_{l}$ until the profit sharing threshold $\tilde{\Pi}$ is reached, and at rate $\alpha_{h}$ afterwards, the expected present value of this contribution is

$$
\begin{gathered}
f(K, \Theta)=E_{0}\left[\int_{0}^{T} e^{-r t} \Pi_{K}\left(K, \Theta ; \alpha_{l}\right) d t+\int_{T}^{\infty} e^{-r t} \Pi_{K}\left(K, \Theta ; \alpha_{h}\right) d t \mid K_{0}=K, \Theta_{0}=\Theta\right] \\
=E_{0}\left[\int_{0}^{T} e^{-r t} \Pi_{K}\left(K, \Theta ; \alpha_{l}\right) d t+e^{-r T} \int_{T}^{\infty} e^{-r(t-T)} \Pi_{K}\left(K, \Theta ; \alpha_{l}\right) d t \mid K_{0}=K, \Theta_{0}=\Theta\right] \\
=E_{0}\left[\int_{0}^{T} e^{-r t} \Pi_{K}\left(K, \Theta ; \alpha_{l}\right) d t+e^{-r T} f\left(K, \tilde{\Theta} ; \alpha_{h}\right) \mid K_{0}=K, \Theta_{0}=\Theta\right] \\
=E_{0}\left[\int_{0}^{\infty} e^{-r t} \Pi_{K}\left(K, \Theta ; \alpha_{l}\right) d t+e^{-r T}\left[f\left(K, \tilde{\Theta} ; \alpha_{h}\right)-f\left(K, \tilde{\Theta} ; \alpha_{l}\right)\right] \mid K_{0}=K, \Theta_{0}=\Theta\right] \\
=\frac{\Pi_{K}(K, \Theta)}{\delta\left(x_{l}\right)}+\frac{\left(\delta\left(x_{l}\right)-\delta\left(x_{h}\right)\right) \Pi_{K}(K, \tilde{\Theta})}{\delta\left(x_{l}\right) \delta\left(x_{h}\right)}\left(\frac{\Theta}{\tilde{\Theta}}\right)^{\beta_{1}\left(x_{l}\right)},
\end{gathered}
$$


where $T$ indicates the first value of $t$ such that $\Theta$ reaches the trigger $\tilde{\Theta}$.

The boundary conditions for (27) are:

$$
\begin{aligned}
v\left(K, \Theta^{*}\right) & =p_{K}, \\
v_{\Theta}\left(K, \Theta^{*}\right) & =0, \\
a_{2}\left(K, x_{l}\right) & =0, \\
a_{1}\left(\bar{K}, x_{l}\right) & =0 .
\end{aligned}
$$

As usual (28) and (29) are the VMC and SPC for the firm's optimal policy. Moreover, (30) imposes the irreversibility constraint on capital $d K \geq 0$. The last condition (31) imposes that $K \leq \bar{K}$.

Substituting (27) into (28) and (29), we have

$$
\begin{aligned}
& \frac{\Psi_{K}(K) \Theta^{*}}{\delta\left(x_{l}\right)}+\frac{\left(\delta\left(x_{l}\right)-\delta\left(x_{h}\right)\right) \Psi_{K}(K) \tilde{\Theta}}{\delta\left(x_{l}\right) \delta\left(x_{h}\right)}\left(\frac{\Theta^{*}}{\tilde{\Theta}}\right)^{\beta_{1}\left(x_{l}\right)}+a_{1}\left(K, x_{l}\right)\left(\Theta^{*}\right)^{\beta_{1}\left(x_{l}\right)}=p_{K}, \\
& \frac{\Psi_{K}(K) \Theta^{*}}{\delta\left(x_{l}\right)}+\beta_{1}\left(x_{l}\right) \frac{\left(\delta\left(x_{l}\right)-\delta\left(x_{h}\right)\right) \Psi_{K}(K) \tilde{\Theta}}{\delta\left(x_{l}\right) \delta\left(x_{h}\right)}\left(\frac{\Theta^{*}}{\tilde{\Theta}}\right)^{\beta_{1}\left(x_{l}\right)}+\beta_{1}\left(x_{l}\right) a_{1}\left(K, x_{l}\right)\left(\Theta^{*}\right)^{\beta_{1}\left(x_{l}\right)}=0 .
\end{aligned}
$$

Easy computation yields

$$
\Theta^{*}(K) \equiv \Theta_{P C}^{*}(K) \equiv \frac{\beta_{1}\left(x_{l}\right)}{\beta_{1}\left(x_{l}\right)-1} \delta\left(x_{l}\right) \frac{p_{K}}{\Psi_{K}(K)} .
$$

Since $\Psi_{K}(K)$ is decreasing in $K$, this identifies an upward-sloping curve. From conditions (28) and (29) we also obtain

$$
\begin{gathered}
a_{1}\left(K, x_{l}\right)=-\left(\frac{\beta_{1}\left(x_{l}\right)-1}{p_{K}}\right)^{\beta_{1}\left(x_{l}\right)-1}\left(\frac{\Psi_{K}(K)}{\beta_{1}\left(x_{l}\right) \delta\left(x_{l}\right)}\right)^{\beta_{1}\left(x_{l}\right)} \\
-\frac{\left(\delta\left(x_{l}\right)-\delta\left(x_{h}\right)\right) \Psi_{K}(K)}{\delta\left(x_{l}\right) \delta\left(x_{h}\right)}\left(\frac{\Psi(K)}{\tilde{\Pi}}\right)^{\beta_{1}\left(x_{l}\right)-1} .
\end{gathered}
$$

Finally, we need to show that the investment policy (32) is viable and optimal at $\tilde{\Pi}$. On the latter point, it must be that $\widetilde{\Theta}$ and $\Theta^{*}$ coincide when the constraint is binding. Now, define $\tilde{K}$ as the largest $K \leq \bar{K}$ that satisfies

$$
\widetilde{\Theta}(\tilde{K}) \equiv \frac{\tilde{\Pi}}{\Psi(\tilde{K})}=\frac{\beta_{1}\left(x_{l}\right)}{\beta_{1}\left(x_{l}\right)-1} \delta\left(x_{l}\right) \frac{p_{K}}{\Psi_{K}(\tilde{K})} \equiv \Theta^{*}(\tilde{K}) .
$$

\footnotetext{
${ }^{17}$ In other words, when $\Theta$ is very small the expected present value of the last unit of capital installed is close to zero. Therefore, the value of the marginal option to scrap it is almost infinite. For further details on the boundary conditions see Dixit and Pindyck (1994, Ch. 5 and 6).
} 
Given decreasing returns to scale, it easy to show that $\tilde{K}$ exists and is unique. Furthermore, for all $K \leq \tilde{K}$ it turns out that $\Theta^{*}(K) \leq \widetilde{\Theta}(K)$ which concludes the first part of the proof.

Let us now turn to the case where $\tilde{K} \leq K \leq \bar{K}$. Notice that now it may well happen that, for given $K>\tilde{K}$, profit first goes beyond $\tilde{\Pi}$ (i.e. $\Theta \geq \widetilde{\Theta}$ ), while at a later stage $\Pi \leq \tilde{\Pi}$ (i.e. $\Theta \leq \widetilde{\Theta}$ ). In this case, in line with the spirit of the mechanism at stake, the price cap goes back to its original level. Recalling (24), the Bellman equations will be

$$
\begin{gathered}
r V(K, \Theta)= \\
=\Pi(K, \Theta)+\left(r-\delta\left(x_{l}\right)\right) \Theta V_{\Theta}(K, \Theta)+\frac{\sigma^{2}}{2} \Theta^{2} V_{\Theta \Theta}(K, \Theta) \\
\text { for } \Theta \leq \widetilde{\Theta}
\end{gathered}
$$

and

$$
\begin{gathered}
r V(K, \Theta)= \\
=\Pi(K, \Theta)+\left(r-\delta\left(x_{h}\right)\right) \Theta V_{\Theta}(K, \Theta)+\frac{\sigma^{2}}{2} \Theta^{2} V_{\Theta \Theta}(K, \Theta) \\
\text { for } \Theta \geq \widetilde{\Theta}
\end{gathered}
$$

Therefore, by the same line of reasoning, the contribution of the $K t h$ unit of capital to the firm's value can be evaluated using (27)-(31) for $\Theta \leq \widetilde{\Theta}$ with (32) as optimal policy. On the other hand, eliminating the dependence on $\tilde{\Pi}$ for the case $\Theta \geq \widetilde{\Theta}$, yields

$$
v(K, \Theta)=\frac{\Pi_{K}(K, \Theta)}{\delta\left(x_{h}\right)}+\sum_{i=1}^{2} a_{i}\left(K, x_{h}\right) \Theta^{\beta_{i}\left(x_{h}\right)} .
$$

The boundary conditions are

$$
\begin{aligned}
v\left(K, \Theta^{*}\right) & =p_{K} \\
v_{\Theta}\left(K, \Theta^{*}\right) & =0 \\
a_{2}\left(K, x_{h}\right) & =0 \\
a_{1}\left(\bar{K}, x_{h}\right) & =0
\end{aligned}
$$

The optimal policy and the integration constant are

$$
\Theta^{*}(K) \equiv \Theta_{P S}^{*}(K) \equiv \frac{\beta_{1}\left(x_{h}\right)}{\beta_{1}\left(x_{h}\right)-1} \delta\left(x_{h}\right) \frac{p_{K}}{\Psi_{K}(K)}, \text { for } \Theta \geq \widetilde{\Theta}
$$


and

$$
a_{1}\left(K, x_{h}\right)=-\left(\frac{\beta_{1}\left(x_{h}\right)-1}{p_{K}}\right)^{\beta_{1}\left(x_{h}\right)-1}\left(\frac{\Psi_{K}(K)}{\beta_{1}\left(x_{h}\right) \delta\left(x_{h}\right)}\right)^{\beta_{1}\left(x_{h}\right)}<0
$$

This concludes the proof

\subsection{Proof of Proposition 3}

To compute the firm's value let us start with the interval $K \geq \tilde{K}$. Solving (36) for $\Theta \in\left(\widetilde{\Theta}(K), \Theta^{*}(K) \equiv \Theta_{P S}^{*}(K)\right)$ yields:

$$
V(K, \Theta)=\frac{\Pi(K, \Theta)}{\delta\left(x_{h}\right)}+\sum_{i=1}^{2} A_{i}\left(K, x_{h}\right) \Theta^{\beta_{i}\left(x_{h}\right)} \text { for } \Theta \geq \widetilde{\Theta} .
$$

In equation (44), the first term is the expected value of profit flows if $K$ is held constant at its current level. As for the second term, $A_{1}\left(K, x_{h}\right) \Theta^{\beta_{i}\left(x_{h}\right)}$ is the value of the firm's optimal future capacity expansion in response to the evolution of $\Theta$ towards the optimal investment policy $\Theta^{*}(K)$. Therefore $A_{1}\left(K, x_{h}\right)$ must be positive. On the contrary, the term $A_{2}\left(K, x_{h}\right) \Theta^{\beta_{i}\left(x_{h}\right)}$ is the expected present value of returning below the Profit Sharing constraint (i.e. $\Theta \leq \widetilde{\Theta})$ in the future: $A_{2}\left(K, x_{h}\right)$ must be positive as well.

If $\Theta \in(0, \widetilde{\Theta}(K))$, solving (35), gives

$$
V(K, \Theta)=\frac{\Pi(K, \Theta)}{\delta\left(x_{l}\right)}+\sum_{i=1}^{2} A_{i}\left(K, x_{l}\right) \Theta^{\beta_{i}\left(x_{l}\right)} \text { for } \Theta \leq \widetilde{\Theta} .
$$

To compute the value function, we use the boundary condition $V(K, 0)=0$, which implies that $A_{2}\left(K, x_{l}\right)=0$. The other term $A_{1}\left(K, x_{l}\right) \Theta^{\beta_{1}\left(x_{l}\right)}$ represents the consequences of reaching the profit sharing constraint in the future (from above) in case the profit flow is reduced. This implies that $A_{1}\left(K, x_{l}\right)$ must be negative.

So far we have three constants $A_{1}\left(K, x_{h}\right), A_{2}\left(K, x_{h}\right)$ and $A_{1}\left(K, x_{l}\right)$ to be determined. To this end, we assume that the value function is continuously differentiable at $\widetilde{\Theta}(K)=\tilde{\Pi} / \Psi(K)$ where the two regimes meet

$$
\begin{gathered}
\frac{\Pi(K, \tilde{\Theta}(K))}{\delta\left(x_{h}\right)}+\sum_{i=1}^{2} A_{i}\left(K, x_{h}\right) \tilde{\Theta}(K)^{\beta_{i}\left(x_{h}\right)}= \\
=\frac{\Pi(K, \tilde{\Theta}(K))}{\delta\left(x_{l}\right)}+A_{1}\left(K, x_{l}\right)(\tilde{\Theta}(K))^{\beta_{1}\left(x_{l}\right)}
\end{gathered}
$$




$$
\begin{gathered}
\frac{\Pi(K, \tilde{\Theta}(K))}{\delta\left(x_{h}\right)}+\sum_{i=1}^{2} \beta_{i}\left(x_{h}\right) A_{i}\left(K, x_{h}\right)(\tilde{\Theta}(K))^{\beta_{i}\left(x_{h}\right)}= \\
\quad=\frac{\Pi(K, \tilde{\Theta}(K))}{\delta\left(x_{l}\right)}+\beta_{1}\left(x_{l}\right) A_{1}\left(K, x_{l}\right)(\tilde{\Theta}(K))^{\beta_{1}\left(x_{l}\right)}
\end{gathered}
$$

Finally, by integrating $a_{1}\left(K, x_{h}\right)$, given by $(43)$, we can obtain

$$
\begin{aligned}
A_{1}\left(K, x_{h}\right) & \equiv \int_{K}^{\bar{K}}-a_{1}\left(z, x_{h}\right) d z= \\
& =\left(\frac{\beta_{1}\left(x_{h}\right)-1}{p_{K}}\right)^{\beta_{1}\left(x_{h}\right)-1}\left(\frac{1}{\beta_{1}\left(x_{h}\right) \delta\left(x_{h}\right)}\right)^{\beta_{1}\left(x_{h}\right)} \int_{K}^{\bar{K}}\left(\Psi_{K}(z)\right)^{\beta_{1}\left(x_{h}\right)} d z
\end{aligned}
$$

Suppose now that $K \leq \tilde{K}$. In this case the profit sharing constraint is never binding and for the firm's value the only effective threshold is the investment policy $\Theta^{*}(K) \equiv \Theta_{P C}^{*}(K)$.

For $\Theta \in\left(0, \Theta^{*}(K) \equiv \Theta_{P C}^{*}(K)\right)$, solving (25), the value function is:

$$
V(K, \Theta)=\frac{\Pi(K, \Theta)}{\delta\left(x_{l}\right)}+\sum_{i=1}^{2} A_{i}\left(K, x_{l}\right) \Theta^{\beta_{i}\left(x_{l}\right)} \text { for } \Theta \leq \Theta^{*}
$$

Again, to compute (49) we use the boundary condition $V(K, 0)=0$, which implies that $A_{2}\left(K, x_{l}\right)=0$. Differently from (45), the term, $A_{1}\left(K, x_{l}\right) \Theta^{\beta_{1}\left(x_{l}\right)}$ represents the value of the firm's optimal future capacity expansion, in response to the evolution of $\Theta$ towards the optimal investment policy $\Theta^{*}(K)$. Yet, differently from (44), here we should take into account the possible switches in the state variable $\Theta$.

By integrating (33) yields $A_{1}\left(K, x_{l}\right)^{18}$

$$
\begin{aligned}
A_{1}\left(K, x_{l}\right) & \equiv \int_{z=K}^{\bar{K}}-a_{1}\left(z, x_{l}\right) d z= \\
& =\left(\frac{\beta_{1}\left(x_{l}\right)-1}{p_{K}}\right)^{\beta_{1}\left(x_{l}\right)-1}\left(\frac{1}{\beta_{1}\left(x_{l}\right) \delta\left(x_{l}\right)}\right)^{\beta_{1}\left(x_{l}\right)} \int_{z=K}^{\bar{K}}\left(\Psi_{K}(z)\right)^{\beta_{1}\left(x_{l}\right)} d z+ \\
& +\frac{\left(\delta\left(x_{l}\right)-\delta\left(x_{h}\right)\right)}{\delta\left(x_{l}\right) \delta\left(x_{h}\right)} \int_{z=K}^{\bar{K}} \Psi_{K}(z)\left(\frac{\Psi(z)}{\tilde{\Pi}}\right)^{\beta_{1}\left(x_{l}\right)-1} d z
\end{aligned}
$$

\footnotetext{
${ }^{18}$ Notice that if $\tilde{K}=\bar{K}$ the constraint $\tilde{\Pi}$ disappears.
} 
This shows that the introduction of a profit sharing threshold $\tilde{\Pi}$ decreases the firm's value.

Finally, by Lemma 1, the comparison of (32) and (42) involves a change in the optimal policy during the period of optimization, i.e. there is a discontinuous jump in the optimal policy at $K=\tilde{K}$. However, we can show that firm's value does not display any discrete jump.

Defining by $(42) \Theta_{P S}^{*}(\tilde{K})$ be the state's value immediately after the jump, while by $(32) \Theta_{P C}^{*}(\tilde{K})$ is the value before the jump, the firm waits until the stochastic process $\Theta$ moves it vertically to $\Theta_{P S}^{*}(\tilde{K})$ before adding a new unit under the Profit Sharing regulation. As the Profit Sharing constraint is exogenously set by the regulator when it is not binding the optimal investment policy is determined by matching and smooth pasting the firm's value function. At the point where the constraint binds, the optimal policy is given by an indifference condition before and after the jump in $x$. This requires the following necessary condition at $\left(\tilde{K}, \Theta^{*}(\tilde{K})\right)$ (Kamien and Schwartz, 1991, p.247):

$$
\begin{gathered}
\frac{\Pi\left(\tilde{K}, \Theta_{P C}^{*}(\tilde{K})\right)}{\delta\left(x_{l}\right)}+A_{1}\left(K, x_{l}\right)\left(\Theta_{P C}^{*}(\tilde{K})\right)^{\beta_{1}\left(x_{l}\right)}= \\
=\frac{\Pi\left(\tilde{K}, \Theta_{P S}^{*}(\tilde{K})\right)}{\delta\left(x_{h}\right)}+\sum_{i=1}^{2} A_{i}\left(K, x_{h}\right)\left(\Theta_{P S}^{*}(\tilde{K})\right)^{\beta_{i}\left(x_{h}\right)} .
\end{gathered}
$$

which ensures that regime switches do not cause any discrete change in the firm's value. 


\section{References}

[1] Ai, C. and D. Sappington (2002), The Impact of State Incentive Regulation on the U.S. Telecommunincations Industry, Journal of Regulatory Economics, 22, 133-60.

[2] Armstrong, M., S. Cowan and J. Vickers (1995), Regulatory Reform. Economic Analysis and British Experience, MIT Press, Cambridge, Mass.

[3] Beesley, M. and S. Littlechild (1989), The Regulation of Privatized Monopolies in the United Kingdom, Rand Journal of Economics, 20, 454-72.

[4] Bernanke, B.S. (1983), Irreversibility, Uncertainty, and Cyclical Investment, Quarterly Journal of Economics, 98, 85-103.

[5] Burns, P., R. Turvey and T. G. Weyman-Jones (1998), The Behavior of the Firm under Alternative Regulatory Constraints, Scottish Journal of Political Economy, 45(2), 133-57

[6] Crew, M. and P. Kleindorfer (1996), Incentive Regulation in the United Kingdom and the United States: Some Lessons, Journal of Regulatory Economics, 9, 211-25.

[7] Dixit, A. (1991), Irreversible Investment with Price Ceilings, Journal of Political Economy, 99, 541-57.

[8] Dixit, A. (1995), Irreversible Investment with Uncertainty and Scale Economies, Journal of Economic Dynamics and Control, 19, 327-50.

[9] Dixit, A. and R.S. Pindyck (1994), Investment under Uncertainty, Princeton University Press.

[10] Dixit, A. and R.S. Pindyck (2000), Expandability, Reversibility, and Optimal Capacity Choice, in M.J. Brennan and L. Trigeorgis (eds.) Project Flexibility, Agency, and Competition, Oxford University Press.

[11] Harrison J.M., (1985), Brownian Motion and Stochastic Flow Systems, New York: John Wiley \& Son.

[12] Kamien, M.T. and N.L. Schwartz (1991), Dynamic Optimization, Amsterdam, North-Holland. 
[13] Laffont, J. J. and J. Tirole (1986), Using Cost Observations to Regulate Firms, Journal of Political Economy, vol.94, 614-41.

[14] Lyon, T. (1996), A Model of Sliding-Scale Regulation, Journal of Regulatory Economics, 9, 227-47.

[15] Lyon, T. and J. Mayo (2000), Regulatory Opportunism and Investment behavior: Evidence from the U.S. Electricity Utility Industry, Indiana University Discussion Paper.

[16] Mayer, C. and J. Vickers (1996), Profit-Sharing Regulation: An Economic Appraisal, Fiscal Studies, 17, 1-18.

[17] McDonald, R. and D. Siegel (1986), The Value of Waiting to Invest, Quarterly Journal of Economics, 101, 707-28.

[18] Merton, R.C. (1990), Continuous-Time Finance, Blackwell's, Cambridge, Mass..

[19] Panteghini, P.M. and C. Scarpa (2003a), The Distributional Efficiency of Alternative Regulatory Regimes: A Real Option Approach, International Tax and Public Finance, 10, 403-18.

[20] Panteghini, P.M. and C. Scarpa (2003b), Irreversible Investments and Regulatory Risk, CES-ifo Working Paper No. 934

[21] Sappington, D. and D. Weisman (1996), Revenue Sharing in Incentive Regulation Plans, Information Economics and Policy, 8, 229-48.

[22] Sappington, D. (2002), Price Regulation and Incentives, in M. Cave, S. Majumdar, I. Vogelsang (eds.), Handbook of Telecommunications, North-Holland, London.

[23] Trigeorgis, L. (1996), Real Options, Managerial Flexibility and Strategy in Resource Allocation, MIT Press, Cambridge, Mass..

[24] Weisman, D.L. (1993), Superior Regulatory Regimes in Theory and in Practice, Journal of Regulatory Economics, 5, 355-66.

[25] Weisman, D.L. (2002), Is There "Hope" for Price Cap Regulation?, Information Economics and Policy, 14, 349-370. 


\section{CESifo Working Paper Series}

(for full list see www.cesifo.de)

976 Assar Lindbeck, An Essay on Welfare State Dynamics, July 2003

977 Henrik Jordahl and Luca Micheletto, Optimal Utilitarian Taxation and Horizontal Equity, July 2003

978 Martin D. D. Evans and Richard K. Lyons, Are Different-Currency Assets Imperfect Substitutes?, July 2003

979 Thorsten Bayindir-Upmann and Frank Stähler, Market Entry Regulation and International Competition, July 2003

980 Vivek Ghosal, Firm and Establishment Volatility: The Role of Sunk Costs, Profit Uncertainty and Technological Change, July 2003

981 Christopher A. Pissarides, Unemployment in Britain: A European Success Story, July 2003

982 Wolfgang Buchholz, Richard Cornes, and Wolfgang Peters, On the Frequency of Interior Cournot-Nash Equilibria in a Public Good Economy, July 2003

983 Syed M. Ahsan and Panagiotis Tsigaris, Choice of Tax Base Revisited: Cash Flow vs. Prepayment Approaches to Consumption Taxation, July 2003

984 Campbell Leith and Jim Malley, A Sectoral Analysis of Price-Setting Behavior in US Manufacturing Industries, July 2003

985 Hyun Park and Apostolis Philippopoulos, Choosing Club Membership under Tax Competition and Free Riding, July 2003

986 Federico Etro, Globalization and Political Geography, July 2003

987 Dan Ariely, Axel Ockenfels and Alvin E. Roth, An Experimental Analysis of Ending Rules in Internet Auctions, July 2003

988 Paola Conconi and Carlo Perroni, Self-Enforcing International Agreements and Domestic Policy Credibility, July 2003

989 Charles B. Blankart and Christian Kirchner, The Deadlock of the EU Budget: An Economic Analysis of Ways In and Ways Out, July 2003

990 M. Hasham Pesaran and Allan Timmermann, Small Sample Properties of Forecasts from Autoregressive Models under Structural Breaks, July 2003 
991 Hyun Park, Apostolis Philippopoulos and Vangelis Vassilatos, On the Optimal Size of Public Sector under Rent-Seeking competition from State Coffers, July 2003

992 Axel Ockenfels and Alvin E. Roth, Late and Multiple Bidding in Second Price Internet Auctions: Theory and Evidence Concerning Different Rules for Ending an Auction, July 2003

993 Pierre Salmon, The Assignment of Powers in an Open-ended European Union, July 2003

994 Louis N. Christofides and Chen Peng, Contract Duration and Indexation in a Period of Real and Nominal Uncertainty, July 2003

995 M. Hashem Pesaran, Til Schuermann, Björn-Jakob Treutler, and Scott M. Weiner, Macroeconomic Dynamics and Credit Risk: A Global Perspective, July 2003

996 Massimo Bordignon and Sandro Brusco, On Enhanced Cooperation, July 2003

997 David F. Bradford, Addressing the Transfer-Pricing Problem in an Origin-Basis X Tax, July 2003

998 Daniel Gros, Who Needs Foreign Banks?, July 2003

999 Wolfram Merzyn and Heinrich W. Ursprung, Voter Support for Privatizing Education: Evidence on Self-Interest and Ideology, July 2003

1000 Jo Thori Lind, Fractionalization and the Size of Government, July 2003

1001 Daniel Friedman and Donald Wittman, Litigation with Symmetric Bargaining and TwoSided Incomplete Information, July 2003

1002 Matthew Clarke and Sardar M. N. Islam, Health Adjusted GDP (HAGDP) Measures of the Relationship Between Economic Growth, Health Outcomes and Social Welfare, July 2003

1003 Volker Grossmann, Contest for Attention in a Quality-Ladder Model of Endogenous Growth, August 2003

1004 Marcel Gérard and Joan Martens Weiner, Cross-Border Loss Offset and Formulary Apportionment: How do they affect multijurisdictional firm investment spending and interjurisdictional tax competition?, August 2003

1005 Burkhard Heer, Nonsuperneutrality of Money in the Sidrauski Model with Heterogeous Agents, August 2003

1006 V. Anton Muscatelli, Piergiovanna Natale, and Patrizio Tirelli, A Simple and Flexible Alternative to the Stability and Growth Pact Deficit Ceilings. Is it at hand?, August 2003

1007 Reto Foellmi and Josef Zweimüller, Inequality and Economic Growth: European Versus U.S. Experiences, August 2003 
1008 James S. Costain and Michael Reiter, Business Cycles, Unemployment Insurance, and the Calibration of Matching Models, August 2003

1009 Marco Runkel, Optimal Contest Design when the Designer's Payoff Depends on Competitive Balance, August 2003

1010 Donald O. Parsons, Torben Tranaes and Helene Bie Lilleør, Voluntary Public Unemployment Insurance, August 2003

1011 Rüdiger Pethig and Andreas Wagener, Profit Tax Competition and Formula Apportionment, August 2003

1012 Johan Willner, Privatisation and Public Ownership in Finland, August 2003

1013 Seppo Kari and Jouko Ylä-Liedenpohja, Taxation and Valuation of International Real Investments, August 2003

1014 James Heckman, Rosa Matzkin and Lars Nesheim, Simulation and Estimation of Hedonic Models, August 2003

1015 Biswa N. Bhattacharyay, Towards a Macro-Prudential Leading Indicators Framework for Monitoring Financial Vulnerability, August 2003

1016 J. Stephen Ferris and Stanley L. Winer, Searching for Keynes: With Application to Canada, 1870-2000, August 2003

1017 Massimo Bordignon, Luca Colombo and Umberto Galmarini, Fiscal Federalism and Endogenous Lobbies' Formation, August 2003

1018 Annette Alstadsæter, The Dual Income Tax and Firms' Income Shifting through the Choice of Organizational Form and Real Capital Investments, August 2003

1019 Peter Fredriksson and Bertil Holmlund, Optimal Unemployment Insurance Design: Time Limits, Monitoring, or Workfare?, August 2003

1020 Kashif S. Mansori, Following in their Footsteps: Comparing Interest Parity Conditions in Central European Economies to the Euro Countries, August 2003

1021 Christoph Borgmann and Matthias Heidler, Demographics and Volatile Social Security Wealth: Political Risks of Benefit Rule Changes in Germany, August 2003

1022 Kjell Erik Lommerud, Bjørn Sandvik and Odd Rune Staume, Good Jobs, Bad Jobs and Redistribution, August 2003

1023 Patrick Karl O'Brien, The Governance of Globalization: The Political Economy of Anglo-American Hegemony, 1793-2003, September 2003

1024 Antonio Ciccone and Giovanni Peri, Skills' Substitutability and Technological Progress: U.S. States 1950-1990, September 2003 
1025 Bjørn Sandvik, Optimal Taxation and Normalisations, September 2003

1026 Massimo Bordignon and Gilberto Turati, Bailing Out Expectations and Health Expenditure in Italy, September 2003

1027 José A. Herce, Namkee Ahn, Ricard Génova, and Joaquín Pereira, Bio-Demographic and Health Aspects of Ageing in the EU, September 2003

1028 John Komlos and Marieluise Baur, From the Tallest to (One of) the Fattest: The Enigmatic Fate of the American Population in the $20^{\text {th }}$ Century, September 2003

1029 Stefan Napel and Mika Widgrén, Bargaining and Distribution of Power in the EU's Conciliation Committee, September 2003

1030 Kai Li and Dale J. Poirier, Relationship Between Maternal Behavior During Pregnancy, Birth Outcome, and Early Childhood Development: An Exploratory Study, September 2003

1031 Ivar Ekeland, James J. Heckman, and Lars Nesheim, Identifcation and Estimation of Hedonic Models, September 2003

1032 Kjetil Bjorvatn and Alexander W. Cappelen, Decentralization and the Fate of Minorities, September 2003

1033 Lars-Erik Borge and Jørn Rattsø, The Relationships Between Costs and User Charges: The Case of a Norwegian Utility Service, September 2003

1034 Maureen Were and Nancy N. Nafula, An Assessment of the Impact of HIV/AIDS on Economic Growth: The Case of Kenya, September 2003

1035 A. Lans Bovenberg, Tax Policy and Labor Market Performance, September 2003

1036 Peter Birch Sørensen, Neutral Taxation of Shareholder Income: A Norwegian Tax Reform Proposal, September 2003

1037 Roberta Dessi and Sheilagh Ogilvie, Social Capital and Collusion: The Case of Merchant Guilds, September 2003

1038 Alessandra Casarico and Carlo Devillanova, Capital-skill Complementarity and the Redistributive Effects of Social Security Reform, September 2003

1039 Assaf Razin and Efraim Sadka, Privatizing Social Security Under Balanced-Budget Constraints: A Political-Economy Approach, September 2003

1040 Michele Moretto, Paolo M. Panteghini, and Carlo Scarpa, Investment Size and Firm's Value under Profit Sharing Regulation, September 2003 